\title{
The Politics and Drivers Underpinning Africa-Europe Research and Innovation Cooperation
}

\section{Andrew Cherry and Daan du Toit}

\begin{abstract}
This chapter provides a critical reflection on the achievements, over the last ten years, of the Africa-Europe partnership in science, technology and innovation (STI), following the introduction of the Joint Africa-EU Strategy in 2007. Building on the CAAST-Net experience and knowledge, the authors assess the multiple drivers (be they political, economic, scientific or even diplomatic) that boosted bi-regional cooperation on STI. In emphasising the political interests and constraints that significantly affect such cooperation, the authors show the rich potential of STI as a unique set of tools to address increasingly internationalised issues on the global scene.
\end{abstract}

\footnotetext{
A. Cherry $(\bowtie)$

Association of Commonwealth Universities, London, UK

D. du Toit

Department of Science and Technology, International Cooperation and Resources, Pretoria, South Africa
}

(C) The Author(s) 2018

A. Cherry et al. (eds.), Africa-Europe Research and Innovation

Cooperation, https://doi.org/10.1007/978-3-319-69929-5_1 
Keywords Joint Africa-EU Strategy • Africa-EU Summits • Science, technology and innovation $\bullet$ STI for development $\bullet$ R4D $\bullet$ Bi-regional partnership - Institutional relationships - Co-ownership • Bi-regional cooperation - Science diplomacy $\bullet$ Political and economic impact • Networked science - Human capital development - Policy and programme coordination

\section{INTRODUCTION}

The convening in Abidjan during November 2017 of the fifth Africa-EU (European Union) Summit of Heads of State and Government provides an appropriate moment to reflect on the achievements of bi-regional cooperation between Africa and Europe in science, technology and innovation (STI) over the past decade. For the purpose of this chapter, biregional cooperation relates to political and operational partnerships in STI and allied domains pursued within the ambit of the Joint Africa-EU Strategy (JAES) (see African Union \& European Union 2010)-a political framework adopted at the second Africa-EU Summit held in 2007 in Lisbon. The chapter's focus is not therefore on the broad, diverse and long-term landscape of scientific partnerships between the two continents, which, due to its complexity and scope, would be difficult to meaningfully assess, but is on a relatively recent and discrete component of this landscape borne of the JAES.

Over the same ten-year period, the CAAST-Net platform, formally launched at the beginning of 2008, has developed a valuable repository of knowledge and information on aspects of Africa-EU cooperation and on the Africa-EU bi-regional STI partnership (see https://CAAST-Net-plus. org/, 2017; Africa-EU Cooperation 2017). CAAST-Net is a valuable, perhaps unique, resource in understanding the achievements and the challenges experienced by the bi-regional partnership.

The 2017 Summit will seek renewed commitment to our STI partnership, building on these achievements and challenges. The timing is opportune to draw on CAAST-Net's accumulated resources to better understand the complicated political, economic and scientific context in which bi-regional cooperation is being promoted. Such an understanding will inform recommendations to continue to enhance our future 
cooperation. Thus, it is largely through the lens of the CAAST-Net experience that we reflect on the politics and drivers underpinning Africa-EU cooperation in STI.

\section{Overview of the Chapter}

Reflecting on the Africa-EU STI partnership first necessitates a better understanding of political context at the time of its gestation and emergence, and the drivers which motivated the efforts to promote an STI partnership. Analysing these conditions, which are not necessarily the same for Africa and Europe, offers a deeper understanding of the nature of the evolving relationship, its strengths and its future potential, on the mobilisation of resources, and of its scope for influence on other dimensions of the Africa-EU relationship and JAES.

The STI partnership between Africa and Europe cannot be considered in isolation of wider political relations between the two regions, especially given the dominant role of the institutions of the African Union (AU) and the EU (and, to some extent, their member states) in promoting this cooperation. With resources invested in and decisions pertaining to biregional cooperation taking place almost exclusively at governmental level, the context for cooperation is intrinsically political. At times, this overtly political context has led to some frustration, particularly, for example, among those in the scientific community, not accustomed to such a process.

After a brief review of this political context, we discuss a range of drivers and objectives that we consider to have played a part in motivating biregional cooperation, along with political and economic considerations, the factors inherent to collaboration to advance excellence in science, as well as aspects related to the institutional relationship between the AU and the EU. We then assess the degree to which actual cooperation activities undertaken over the past ten years (and their results) correspond to the political context and to the drivers that informed both regions' commitment to the STI partnership. In doing so, we also consider the evolution of the political context and the drivers for cooperation over the past decade. We conclude with a glance to the future and, without pre-empting what follows, offer initial policy-level recommendations on how biregional cooperation might be further enhanced. 
Nevertheless, it should be noted that the seeds sown during the past decade to promote bi-regional cooperation may only bear fruit in the years ahead. The existence of the formal bi-regional partnership within a wider landscape can hinder the direct attribution of outcomes and impact to political and programming efforts at promoting cooperation. Attribution is further complicated by significant time lag between cause and effect.

Our Africa-EU STI partnership is unique and fast evolving. Its place within, and relationship to, the wider cooperation landscape is complex. Although the assessment of the political context and drivers of the partnership at this ten-year milestone is timely and necessary, it has the potential to be equally complex. We have kept our approach simple, avoiding the detailed analysis that would be pertinent yet beyond the remit of this book. It is our intention that this brief assessment, albeit a highly subjective exercise, provides relevant background to the chapters that follow and offers a practitioner's perspective to students of Africa-Europe relations, helping to inform opinions of the achievements and merits of the past decade of partnership, and in formulating appropriate recommendations to improve our future cooperation.

\section{The Political Context for Bi-Regional Cooperation}

\section{Towards Equal Partnerships}

The political context for Africa-Europe relations in 2007 was one that saw the gathering momentum of significant change to the typical post-colonial relationship between Europe and its former colonies that prevailed during the second half of the twentieth century. These years were marked by the Lomé Convention and subsequently by the dispensations of the Cotonou Partnership Agreement, with their primary focus on European development aid to Sub-Saharan Africa and preferential access to European markets for developing countries.

In 2007 discussions on the new Economic Partnership Agreements (EPA) between Europe and different African regions were in full swing, preparing the way for a relationship that would see a greater focus on reciprocity in African and European commitments, for example with regard to trade, and an emphasis on values such as co-ownership and co-responsibility.

In 2007, Africa was represented by a still relatively new AU, established in 2001, with a comprehensive focus on continental cooperation and integration. The development of a cross-sectoral inter-institutional AU-EU 
partnership was shaped largely by the convening of the 2007 Lisbon Summit. The first Africa-EU Summit, held in Cairo in 2000, lacked the focus of the second summit in 2007 on the development of a comprehensive partnership. Whilst there had been contact between the EU and the AU's predecessor, the Organisation for African Unity, those contacts were largely set within the post-colonial context of the second half of the twentieth century. In 2007, the European Commission (EC) found in the African Union Commission (AUC) a counterpart with which to construct a new strategic partnership. Efforts to promote and cement a bi-regional STI partnership will have played a part in solidifying the emerging institutional relationship between the two Unions-and their two Commissions.

While the inter-institutional relationship provides an important context for the STI partnership's emergence, other international relations will also have had an influence. Not least are the bilateral relations between African and European member states, as well as the engagement of individual countries with the bi-regional partnership. For example, the 2007 Summit was convened under the Portuguese Presidency of the EU. Portugal, a country with historic links with Africa, prioritised the Africa-EU partnership on the political agenda for its Presidency. Relations between the EU and Africa's Regional Economic Communities (RECs), the Africa, Caribbean and Pacific (ACP)-EU partnership, and different frameworks for Euro-Mediterranean cooperation, have each had an influence on the shaping of the bi-regional partnership. Thus the availing of financial resources to support the JAES STI partnership can be dependent on decisions of the structures governing these relationships-consider, for instance, the governance of the ACP-EU relationship and the provision of science and technology (S\&T) funds for Africa-EU cooperation under the European Development Fund (EDF).

\section{Global Consensus on STI for Development}

By agreeing in 2007 to include a specific focus on STI in their new partnership, African and European leaders were aligning themselves with an emerging consensus on science for development at that time. The 2002 World Summit on Sustainable Development had explicitly recognised in its Johannesburg Plan of Implementation that science should be an instrument of and not a reward for development. The first decade of the twentyfirst century thus saw intense activity at the policy level, in international forums such as the G8, the OECD, UNESCO or the World Bank on how 
to best harness STI for development (see, e.g. Watkins and Ehst 2008; Juma 2005). The Carnegie Group of G8 science leaders, for example, in 2006 had a dedicated outreach meeting with African partners. In 2002, the ACP Group of States and the EU convened a dedicated forum on research for sustainable development to consider appropriate investments from the EDF to build STI capacity building in ACP countries, a theme which would subsequently receive regular consideration under the JAES. The emergence in 2006-2007 of Africa's Science and Technology Consolidated Plan of Action can also be seen, in the wider context, as another component of this global consensus, giving practical issue to Africa's high-level objective of building strong S\&T constituencies for socio-economic transformation.

The Lisbon Summit, in adopting the JAES, structured Africa-EU cooperation in different partnerships, with STI being grouped together with information and communication technologies (or the information society) and space in the so-called Eighth Partnership. The policy context, which informed this design, was the strong development policy focus on the narrowing of the digital divide especially in the aftermath of the World Summit on the Information Society held in 2003 and 2005, and in which the EU had actively participated. Europe's role as an historic provider of space-based technologies and services to Africa, European efforts to provide Africa with information and data products from Earth observation platforms, and perhaps ambitions to safeguard and expand this role, further cemented the inclusion of space in this framework.

At the time of the Lisbon Summit, despite the close economic and development cooperation links between Africa and Europe, relations between the two regions continued to be marked by political disagreements, often significant. Against this backdrop, the good news story, which cooperation in STI represents, unscathed by political differences or sensitivities with regard to trade or other controversies, meant that science diplomacy had also become a popular currency for the strengthening of the overall Africa-EU partnership. Indeed, in years to come, STI successes, no matter how modest, were often put in the spotlight when the successes of the JAES were to be celebrated.

Not to be confused with the 2007 Lisbon Summit of African and European Heads of State and Government, 2007 also saw the agreement of the Treaty of Lisbon, amending the original constitutional basis of the EU. What marks the Treaty as particularly relevant to our discussion of the Africa-EU STI partnership is the explicit inclusion among the treaty's 
articles of the objective of strengthening the EU's scientific and technological bases towards a European Research Area.

The explicit recognition of the need for continued strengthening and integration of the scientific and technological base in Europe, albeit for economic and industrial competitiveness, provided a sound argument for the inclusion in the JAES of an equivalent commitment to S\&T. What is deemed essential for Europe, and indeed for the world, must surely be equally essential for Africa and for the new, heightened Africa-Europe political relationship in the JAES.

\section{Evolution of Africa-EU Cooperation in Research for Development}

At the time of the launch of the JAES, the research for development community, despite the broad political support for this agenda, had just started cooperation under the recently launched EU's Seventh Framework Programme (FP7) for Research and Innovation. Earlier FP had with some success included dedicated activities to fund research cooperation orientated to development outcomes between European researchers and their developing country partners (especially in areas such as health, agriculture and the environment). The new FP7, however, did not include such a specific activity but instead mainstreamed cooperation with developing countries across all themes of the FP-with developing country participants still being eligible for EU funding. The jury was out on how successful this new approach would be.

The year 2007 thus marked the beginning of a new era of sorts for Africa-EU science cooperation, with a focus on what many saw as a maturing partnership mainstreamed within a broader landscape of international cooperation programmes in science. However, that policy intent and the rhetoric co-existed with a requirement, on the part of several African countries, for concerted international assistance to develop essential STI capacities such as human capital and research infrastructure. The STI capacity building objective was included in the JAES but in the years to come cooperation efforts under the STI partnership were sometimes hampered or confused because of a misalignment between the goals of advancing excellence in science through cooperation as equal partners on the one hand, and European assistance for African capacity building on the other. This manifested itself most clearly in challenges to afford development assistance to Africa through programmes focused on mutual benefit through research cooperation. 
As evidenced by the inclusion of STI in a dedicated partnership with information society and space, the adoption of the JAES also symbolised the broadening of Africa-EU science cooperation to a bigger community and portfolio-beyond the traditional, although extensive and successful history of cooperation in agricultural development research, for example. Timid statements of intent were made with regard to cooperation in emerging and industrial technology areas, but more often than not still within the context of science for development, for example, in the use of nanotechnology for water purification. Perhaps most significantly, the EU declared its intents to develop a dedicated STI policy dialogue with Africa (as it had launched with other regions) and saw the then African Ministerial Council on Science and Technology (AMCOST) as a potential counterpart for this endeavour. The first CAAST-Net project was funded, through the EU's FP7, to prepare and support such a policy dialogue.

\section{Key Drivers Informing Bi-regional CoOperation}

The JAES policy commitments adopted by African and European leaders in Lisbon in 2007 were informed and underpinned by a set of shared drivers for common objectives. In this section we consider the key drivers and objectives for the STI partnership, their relative importance, as well as the differences on the African and European sides.

\section{The Global Consensus on Science and Technology}

We referred in the previous section to an emerging global consensus in the first decade of the twenty-first century on the role of STI in development, and to the explicit inclusion in the Treaty of Lisbon to an objective of building the EU's scientific and technological bases. In short, the widespread acceptance that capacity in scientific and technological research, and in innovation, offered a route to industrial competitiveness, to economic growth, to sustainable development and to poverty alleviation provided a robust and timely argument to the architects of JAES for a chapter on science for sustainable development that was hard to refute. Thus, despite a shortage of resources, $S \& T$ together with space, and information and communication technologies found their place in the JAES as instruments of sustainable development alongside traditional domains for international political relations such as democracy, governance, human rights, peace and security. 


\section{Science Diplomacy}

Although not an explicit driver at the outset, over time both the African and European sides saw, in the inclusion of STI in the JAES framework, potential for science diplomacy: the STI partnership reinforcing the bi-regional relationship via influence in other policy spheres. This contribution would include safeguarding and expanding an historic trading partnership, although as the difficult EPA negotiations in years to come would show, the two sides would harbour different ambitions, with Africa, for example, seeking greater access to the European agricultural market, and with Europe seeking to expand its presence in the African services sector. The global security context and Africa's role as a partner for Europe in the space sector, for example, were also seen as potential beneficiary spheres, at least from the European side, from investment in bi-regional STI cooperation.

Given the strategic significance and continued dominance of development cooperation as the focus of Africa-EU relations, both the African and European sides also harboured ambitions for the bi-regional STI partnership to have an influence on this domain. From an African perspective, there was a strong demand for the partnership to contribute to STI capacity building on the continent. While shared by the European side, the perspective was perhaps nuanced by a desire to see a new dimension added to the historic Africa-EU development cooperation relationship, one that would ensure greater efficiency and deliver greater impact.

As part of the portfolio of science diplomacy objectives, it was also foreseen that the bi-regional STI partnership would contribute to strengthening the AU-EU institutional partnership. As with capacity building, the institutional partnership objective was shared by both sides, again perhaps from slightly different perspectives. From a political angle, the EC could leverage STI cooperation to develop a privileged relationship with the new AUC, whilst the partnership with the EU also provided the AU with opportunities to develop its influence within the continental STI landscape.

\section{Networked Science Knows No Borders}

The sharing of resources, experience and expertise, especially to address shared challenges, or advance frontier science projects, has historically 
been regarded as a major driver for international cooperation in STI. Africa and Europe joining forces and resources to harness science to address major societal challenges such as climate change, energy security or pandemic disease was, thus, also one of the major objectives for JAES' commitment to bi-regional STI cooperation.

Few countries invest in international cooperation in science as a purely altruistic endeavour. Parties typically have to leverage their respective comparative advantages to make them attractive as a partner to the other (e.g. niche expertise in key technology domains or access to unique geographic conditions or resources). It is doubtful whether such strategic considerations informed the development of the bi-regional partnership in any significant manner, other than that Africa was certainly keen to leverage Europe's strong STI capacities. The nature or complexity of the multilateral cooperation relations is such that they can present greater challenges to leveraging national benefits than do bilateral cooperation relations, and offers a perspective on the relative merits of investing in multi- and bilateral relations.

International cooperation also plays a crucial role in developing human capital for STI. Most countries invest heavily in researcher training and mobility programmes with an international dimension, to ensure their next generation of researchers are equipped with global networks and perspectives. From an African perspective, the bi-regional partnership had as an objective to ensure exactly such support for human capital development in Africa. Whether investment in the bi-regional partnership was a major driver for Europe's own human capital development objectives is doubtful, although the publicly stated European policy objective of promoting Europe as a preferred destination for global research talent also applied in Africa.

\section{Enbancing Cooperation: Ensuring Greater Efficiency and Impact}

Cooperation in STI between Africa and Europe did not start with the biregional partnership agreed in Lisbon. Neither did the partnership have ambition to encompass all aspects of cooperation-especially bilateral relations. It is widely understood that the scope and scale of STI cooperation between African and European institutions in a bilateral context are far more extensive than in a bi-regional context and there was a conscious effort not to duplicate that landscape. 
The JAES however did set a major objective of ensuring better coordination and synergy between programmes implemented at the multilateral (AU-EU) level and bilateral initiatives between member states. Addressing the goal would help avoid duplication and ensure greater efficiency, impact and return on investment. The JAES also had the objective of providing greater strategic direction to funding instruments, thus, not only ensuring alignment between different funding instruments and cooperation opportunities available for Africa-EU cooperation but also providing strategic input into the formulation of new cooperation programmes. The STI partnership shared these objectives too, aiming to improve the efficiency of cooperation, for example, with regard to the mobilisation of resources and enhancing impact.

\section{Alignment of Bi-regional Cooperation WITH Supposed Drivers}

Ten years on from the 2007 Lisbon Summit, it is an appropriate moment to reflect on the achievements of the bi-regional partnership. It is relevant at this juncture to distinguish between the policy-level bi-regional partnership in STI governed by the High Level Policy Dialogue (HLPD), and operational thematic research and research for development projects implemented by African-EU partnerships between institutional actors and which are funded by associated programmes or aligned to the objectives of the policy-level partnership. Whilst other chapters in this book cover the outcomes of operational projects, our assessment here concentrates mainly, although not exclusively on the policy-level partnership. We consider the extent to which the partnership's broader achievements have responded to the drivers discussed above.

Any perceived mismatch, however, between original intention and actual achievement should not necessarily be cause for criticism. The efforts in the years preceding 2007 to promote and build a structured, formal bi-regional partnership in STI were, in many respects, pioneering, and the vision was simple and strong. That said, it is inevitable with the benefit of ten years' hindsight, the initial well-intentioned vision and assumptions of the partnership's protagonists may seem naïve or simplistic. The pragmatic agility to adapt to the rapidly changing environment that has been an important feature of the partnership's success thus far and will continue to be so beyond the 2017 Summit. 


\section{Political and Economic Impact}

The STI partnership has enjoyed substantial acclaim. Summits, ministerial gatherings and other high-level events held in the context of our biregional relationship over the past ten years have celebrated the successes of the STI partnership. Public awareness and communication efforts associated with the JAES often put the STI partnership in the spotlight as a flagship of cooperation. Although this celebration takes place in the absence of independent critical analysis, the partnership has achieved and continues to achieve a political purpose, which suits both parties: The STI partnership itself is a tangible demonstration of good-willed collaboration between Africa and Europe, working together at an enhanced policy and programming level for the global good.

Elsewhere, in other policy and programming spheres, within or even beyond the partnership, there have been varying degrees of influence of the STI partnership: There is, for example, no discernible evidence of an influence of the STI partnership on EPA negotiations conducted over the past decade. On the other hand, the JAES STI partnership has been particularly successful in terms of political impact in the strengthening of inter-institutional cooperation between the AUC and the EC. The STI partnership's well-defined governance structure has regular formal meetings. Through these meetings the two services have developed a close and privileged partnership, marked, for example, by staff exchanges. The engagement of member state representatives in governance mechanisms, however, with the exception of that of a relatively small core group, has struggled to function optimally. On the other hand, some critics have argued that the level of EC support to the AUC has been so significantmany of the programmes implemented by the AUC's S\&T department receive EU funding support - that it set the African agenda and potentially undermines the AUC's independence, while also confronting Africa governments with the reality of investing to support AU programmes.

The inclusion of STI as a dedicated focus area in the JAES also had some success in providing a new dimension to the Africa-EU development cooperation partnership. It informed the availing of resources under the Development Cooperation Instrument, to support a range of initiatives such as the African Union Research Grants (AURG) programme implemented by the AUC. An increased allocation of funds for S\&T from the ninth to the tenth EDF is said to be a response to the inclusion of a science partnership 
in JAES, while there was no impact, however, on resources under the EDF, availed to national governments and the RECs. The JAES science partnership does appear to have sparked a renewed interest in STI in the EC's dedicated services for development cooperation, after years of a relative lack of interest.

\section{Expanding the Knowledge Base}

The ten-year course of the JAES science partnership has seen the accumulation of an expansive portfolio of associated Africa-EU cooperation initiatives around scientific and technological research and innovation (R\&I), particularly with a development focus. There is moreover a general consensus, albeit among interested parties, of an expansion of dedicated Africa-EU STI cooperation relative to the pre-partnership period.

Whilst a core tenet of the bi-regional partnership is the pooling of resources and the sharing of experience and expertise, a shadow on this otherwise positive situation is that resourcing of the portfolio of initiatives thus far has been skewed, with most funding originating on the EU side. The coordinated call for Africa is one example of a large contribution to the portfolio supported by the FP7. A noteworthy exception to this observation is provided by the ERAfrica call for proposals, discussed elsewhere in this book, which was funded jointly by a group of African and European national research and development agencies through a common pooling mechanism.

Although the JAES foresaw a stimulation of interest in R\&I partnerships, most of the actual cooperation involved research cooperation between higher education institutions and publically funded organisations, with limited private sector involvement. International innovation partnerships are, however, inherently more difficult to promote than those with a primary orientation towards research, so this was a shortcoming not unique to Africa-EU cooperation.

STI cooperation during JAES has served Africa's human capital development and other capacity building objectives well, with a range of student training and mobility programmes, launched under the Erasmus as well ACP instruments. The bi-regional partnership has also seen valued investment in developing Africa's high-speed research networking capacity, a critical research infrastructure requirement. 


\section{Aligning Efforts}

Strong AUC and EC involvement in the cooperation has not yet attracted strong sustained reciprocal interest from either African or European member states to co-invest and coordinate programmes under the umbrella of the JAES, as was foreseen, although the STI partnership has provided inspiration and additional rationale for national programmes in support of cooperation between Africa and Europe. The multilateral ERAfrica funding programme mentioned above, as well as the more recent LEAP-Agri joint funding programme, also inspired by the JAES STI partnership, has seen African and European research funders joining forces to fund collaborative research partnerships.

On another positive note, efforts since the 2013 Africa-EU HLPD on STI to focus the STI partnership's attention on the area of food and nutrition security and sustainable agriculture (FNSSA) promises to deliver results. An FNSSA R\&I partnership foresees a flexible multilateral funding arrangement supported by African and European programme owners. We already see the leveraging of dedicated resources under at least three aligned research programmes, including the EU's Horizon 2020 FP. Efforts are being made to encourage coordination between public and private actors in this R\&I partnership, although at this early stage without tangible results.

\section{Evolution of the Drivers For Bi-REgIONAL \\ CoOperation}

In Abidjan at the 2017 Summit of Heads of State and Government, Africa and Europe will recommit to the JAES and the bi-regional STI partnership it includes. It is opportune to ask if the drivers, which informed cooperation in 2007, still apply and how they may have evolved.

Profound economic, political, environmental and social changes in Africa and Europe, alongside the international agreements and frameworks responding to these changes, such as the United Nations 2030 Agenda, provide a rapidly evolving context for Africa-EU relations, for the JAES and for the cross-cutting STI partnership. Africa and Europe certainly have much to gain from increased political and economic ties. At the same time, however, the additional bi-regional cooperation opportunities afforded to Africa by the Tokyo International Conference for Africa's Development, or by the Forum on China-Africa Cooperation (FOCAC), adjust Africa's perspective on JAES. Indeed, China is a dominant trade 
and investment partner for Africa and a more substantial analysis might consider how the STI component of JAES compares to that of the FOCAC.

Since 2011 and with the increasing impact of EU's development policy, the so-called Agenda for Change (see European Commission 2017a), the EU's approach to development cooperation is also evolving. There will be different focus areas and eligibility criteria. If the ambition in 2007 was to move beyond a donor-recipient relationship, it will be an imperative in 2017 (see European Commission 2017b) . Beyond 2020, and the expiry of the Cotonou Partnership Agreement, the relationship between Europe and the ACP Group of States will change significantly (see European Commission 2016) while knowledge promotion through the digital economy, STI will be a specific objective.

It is not only the geopolitics that is changing: The entire global enterprise of science is undergoing rapid transformation, perhaps most notably in the context of open science and open innovation, with traditional ways of cooperation discarded for more integrated, dynamic approaches. Open access to scientific data and research results, along with increased investment in e-infrastructures, will enable "networked science", shaping future Africa-EU cooperation in STI. The new bi-regional partnership must respond appropriately or risk obsolescence. Indeed investing in constant exploration and rolling out of new collaborative mechanisms is perhaps one of the partnerships greatest opportunities to contribute to the vigour of the overall Africa-EU landscape.

It would also be interesting to see if the AU's Science, Technology and Innovation Strategy for Africa (STISA-2024) meaningfully influences the design of the future partnership and what role the various national and regional STI strategies that African parties are developing will play. Questions to consider also include the role of the African scientific diaspora in cooperation frameworks and the influence of a coordinated European response to cooperation with Africa-as, for example, debated in the EU's Strategic Forum for International Cooperation.

It is unlikely that economic drivers, including trade and investment objectives, will have a more significant bearing on the future STI partnership than it had in the past. Return on investment, especially for taxpayers in difficult times, will be questions leaders would have to answer. Dynamics such as attracting research and development orientated investment by multinational companies and ambitions to be competitive in technology intensive industries could introduce elements of competition to the "strategic partnership". 


\section{CONCLUSION}

Despite these changing dynamics, or perhaps because of them, bi-regional STI cooperation will more than ever be strategically relevant and important to the wider political partnership between the two regions. The role of STI as a domain with cross-cutting influence should receive attention in Abidjan. Other factors to consider in determining new drivers of cooperation include the evolution of the institutional structures and priorities of both the AU and the EU. Thus, for instance, were an African Space Agency or an African Research Council to become AU priorities for bi-regional cooperation, the nature of the partnership could be dramatically altered. Furthermore, within an integrated STI response to global challenges, for example, promoted in multilateral forums, the value addition of bi-regional cooperation as opposed to more inclusive multilateral cooperation will receive scrutiny and become a driver for cooperation in its own right.

Despite the lofty goals and flowery language of the 2007 Summit outcomes and other strategy documents, it is essential to maintain a realistic perspective with regard to expectations. In a complicated institutional landscape, fraught with political sensitivities, capacity constraints and other challenges, the bi-regional STI partnership was never going to change the world. It never pretended to. As the chapters in this book show, in its first ten years the STI partnership, at both the policy and operational levels, has achieved important successes. These are worth celebration. Perhaps most significantly the investments over the past decade will continue to bear fruits in years to come as they have enabled a more robust and stronger STI partnership.

In a world where multilateralism and solidarity are precious commodities, Africa-Europe bi-regional cooperation continues to matter. STI, because of its cross-cutting impact and strategic significance, should play an ever more central role in this broad political relationship. Africa and Europe should aim to harness this potential, but a dedicated focus, with dedicated instruments to advance cooperation is required, as provided for the bi-regional partnership.

This book will conclude with a more comprehensive analysis on future developments. We hope that it shows that the decision in 2007 to invest in a dedicated bi-regional STI partnership was a correct one. The partnership has achieved much short-term tangible success at the project and policy partnership levels, as well as likely long-term though less tangible impact. However, an honest, perhaps even politically incorrect analysis, without favour or fear, to identify the shortcomings of the past decade as 
this book attempts, should play an important part in informing postAbidjan plans - plans which should marry ambition with realism.

\section{REFERENCES}

Africa-EU Cooperation. (2017). Science, technology and innovation portal. Available from: http://www.rinea.org/en/index.php. Accessed 27 June 2017. African Union \& European Union. (2010). Joint Africa-EU Strategy: Action plan 2011-2013. Available from: http://www.africa-eu-partnership.org/sites/ default/files/documents/03-JAES_action_plan_en.pdf. Accessed 8 May 2017.

European Commission. (2016). Joint communication to the European Parliament and the Council. A renewed partnership with the countries of Africa, the Caribbean and the Pacific. Available from: https://ec.europa.eu/europeaid/ sites/devco/files/joint-communication-renewed-partnership-acp-20161122_ en.pdf. Accessed 25 June 2017.

European Commission. (2017a). EU Communication on the agenda for change. Available from: https://ec.europa.eu/europeaid/policies/european-development-policy/agenda-change_en. Accessed 27 June 2017.

European Commission. (2017b). Joint communication to the European Parliament and the Council for a renewed impetus of the Africa-EU partnership. Available from: https://ec.europa.eu/europeaid/sites/devco/files/joint-communication-renewed-partnership-acp-20161122_en.pdf. Accessed 25 June 2017.

Juma, C. (Ed.). (2005). Going for growth: Science, technology and innovation in Africa. London: The Smith Institute.

Watkins, A., \& Ehst, M. (Eds.). (2008). Science, technology and innovation: Capacity building for sustainable growth and poverty reduction. Washington, DC: The International Bank for Reconstruction and Development/The World Bank.

Open Access This chapter is licensed under the terms of the Creative Commons Attribution 4.0 International License (http://creativecommons.org/licenses/ by $/ 4.0 /$ ), which permits use, sharing, adaptation, distribution and reproduction in any medium or format, as long as you give appropriate credit to the original author(s) and the source, provide a link to the Creative Commons license and indicate if changes were made.

The images or other third party material in this chapter are included in the chapter's Creative Commons license, unless indicated otherwise in a credit line to the material. If material is not included in the chapter's Creative Commons license and your intended use is not permitted by statutory regulation or exceeds the permitted use, you will need to obtain permission directly from the copyright holder.

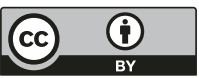

